\title{
Developing and validating the risk perceptions and behavioral responses questionnaire for COVID-19 (Risk PreceptCOVID-19): an application of the extended parallel process model
}

\section{Leila Jahangiry ( $\sigma$ jahangiry@razi.tums.ac.ir)}

Tabriz University of Medical Sciences https://orcid.org/0000-0002-0491-5764

\section{Parvin Sarbakhsh}

Tabriz University of Medical Sciences

Parvin Reihani

Tabriz University of Medical Sciences

Sirous Samei

Azarbaijan Shahid Madani University

\section{Zahara Sohrabi}

Tabriz University of Medical Sciences

Mahmoud Tavousi

Aecer

Ali Mintazeri

AECER

\section{Research}

Keywords: COVID-19, Fear Appeal, Extended parallel process model, instrument, and Psychometric properties

Posted Date: August 12th, 2020

DOl: https://doi.org/10.21203/rs.3.rs-57057/v1

License: (c) (i) This work is licensed under a Creative Commons Attribution 4.0 International License. Read Full License 


\section{Abstract}

Background: In order to understand how people perceive, process, and respond to COVID-19 risk information, a valid and reliable instrument is needed. This study aimed to develop an instrument to measure the risk perceptions of people about COVID-19 based on the Extended Parallel Process Model (EPPM).

Methods: This cross-sectional study was conducted in Tabriz, Iran. First, a comprehensive literature review was conducted to develop the initial draft of Risk-percept COVID-19. Then, in order to obtain a prefinal version of the instrument, face and content validity were conducted. After that, construct validity (exploratory and confirmatory), internal consistency using test-retest reliability and Cronbach's alpha of the instrument were measured.

Results: Forty two item were initially generated. During the content validity, it was reduced to 29 items. The exploratory factor analysis (EFA) revealed four factors (perceived response efficacy, perceived threats (severity and susceptibility), perceived self-efficacy, and defensive responses (denial, avoidance and reactance) that accounted for 49.97 of the observed variance. The confirmatory factor analysis (CFA) designated a model with appropriate fitness for the data. Cronbach's alpha coefficient for the dimensions ranged from .697 to .793, and the Intraclass Correlation Coefficient (ICC) ranged from .71 to .80 within acceptable ranges.

Conclusion: the current findings show that the Risk-percept COVID-19 is a valid and reliable instrument to assess the cognitions and perceptions of adults.

\section{Background}

Corona virus disease (Covid-19), a global pandemic, spread in many countries rapidly [1]. World health organization declared that the most important way to prevent and slaw dawn the transmission of COVID19 is to reduce person-to-person transmission of COVID-19 among general population. Well informing and raising the knowledge of general population is an effective strategy to mitigate and control the current pandemic [2]. It is believed that awareness might persuade people to take appropriate actions toward control COVID-19 [3]. Indeed, in order to influence people's behavior using persuasive messages applying fear appeals is recommended [4].

The extended parallel process model (EPPM) suggests that health risk messages produce two cognitive appraisals including an appraisal of the efficacy of the recommended response and an appraisal of the threat [5]. The model suggests that a fear appeal might work if certain conditions exist including 
response efficacy, self-efficacy, and threats (susceptibility and perceived severity). The model suggests two distinct processes in response to fear appeals; a danger control process and a fear control process [6].

In order to understand how people perceive, process, and respond to COVID-19 risk messages, a valid and reliable instrument is needed. Thus this study aimed to develop an instrument to measure the risk perceptions of people about COVID-19 based on the EPPM. We thought this would allow applying the questionnaire in both epidemiological and interventional studies and also could provide an opportunity for future research to take necessary actions toward COVID-19 control and prevention. The EPPM has many strong properties that make it useful in guiding many decisions of public communication campaigns.

\section{Methods}

\section{Study design and data collection}

This cross-sectional study was conducted in Tabriz, Iran. An online questionnaire was developed for general population. The Ethics Committee of Tabriz University of Medical Sciences approved the study (No: IR.TBZMED.REC.1398.1307). We obtained informed consent from all participants.

\section{Item generation}

The extended parallel process model was used for developing the risk perception and behavioral responses [5] to COVID-19. A comprehensive review of the literature was conducted to create an item pool [7-21]. Members of the research team (PR, SS, and ZS) reviewed the data and generated 150 items. After screening, in total 42 items were selected and divided into four dimensions including perceived response efficacy, perceived self-efficacy, perceived susceptibility and severity. The response efficacy dimension included seven items measuring beliefs about the effectiveness of the recommended response for averting COVID-19. Perceived self-efficacy included nine items t measuring beliefs about people's ability to perform the recommended response to avert COVID-19. Perceived susceptibility included eleven items measuring beliefs about people's risk of experiencing COVID-19. Perceived severity included five items measuring beliefs about the magnitude of COVID-19. Each item is rated on a 5-point Likert-scale ( $1=$ strongly disagree, $2=$ disagree, $3=$ neutral, $4=$ agree, and $5=$ strongly agree). Content validity

Qualitative and quantitative content validity were applied for Risk-Percept QVID-19. A panel of six experts including three health education specialists, a specialist physician in infectious diseases, an epidemiologist and a psychologist evaluated the content validity of the Risk-Percept COVID-19. They assessed the questionnaire in the terms of wording, item allocation, grammar, and scaling. In the quantitative phase, the content validity index (CVI) and content validity ratio (CVR) were tested. Clarity, simplicity, and relevance of the items were measured in CVI assessment [22].

\section{Face validity}


Both qualitative and quantitative methods were used to measure the face validity of the Risk-Percept COVID-19. In the qualitative process, 8 young adults were asked to assess each item of the Risk-Percept COVID-19 to indicate whether they felt it was difficult or ambiguous to answer the items. According to the participants' viewpoint, the difficult and vague items were revised. In the quantitative stage, the impact score (frequency $\times$ importance) was calculated to determine the percentage of participants who recognized items as important on a 5-point Likert scale. Items were found suitable whether they had an impact score equal to or greater than 1.5 [23]. Overall three items had an impact score equal or lower than 1.5 , and 42 items had an impact ranging from 1.8 to 5 . Therefore, the first form of instrument contained 42 items.

\section{Psychometric properties evaluation of the Risk-Percept COVID-19}

In order to test the psychometric properties of the Risk-Percept COVID-19, a cross-sectional study was carried out in Tabriz, Iran. Participants were recruited from online applications and announcements (Telegram, WhatsApp, and Instagram) that ask people to take part in the study. The announcements asked people to take part in the study for control and prevention of COVID-19 and full-fill the study questionnaire. Those interested in participating in the study complete the online questionnaire. In order to estimate an optimal sample size, 5-10 respondents in to one variable ratio was used [24]. The participants had to be 15 years of age or older and having consent to participate in the study.

Data collection was conducted in March 21 to 28, 2020. The high incidence of COVID-19 in Tabriz and the crucial need for a questionnaire to assess educational and interventional programs led to it's selection as study design.

\section{Statistical analysis}

The characteristics of the participants were summarized as numbers, percentages, or means with standard deviations, where appropriate. Several statistical methods were performed to evaluate the psychometric properties of the Risk-Percept COVID-19 as follows.

\section{Exploratory factor analysis}

Exploratory factor analysis (EFA) was applied to identify the main factors of the Risk-Percept COVID-19. According to the number of items in the Risk-Percept COVID-19. A principal component analysis (PCA) with varimax rotation was used to extract the main factors. The Kaiser-Meyer - Olkin (KMO) test and Bartlett's test of sphericity were applied to evaluate the adequacy of the sample for the factor analysis [25]. The factors with an eigenvalue of more than 1 was considered acceptable for factor extraction, and a scree plot was performed to specify the number of factors. Factor loadings equal to or greater than .40 were considered acceptable [26].

\section{Reliability}

\section{Internal consistency}


Cronbach's alpha coefficient was used to measure the internal consistency of each item, the whole scale and each subscale of the Risk-Percept COVID-19. Alpha values of .70 and above were considered acceptable [27].

\section{Test-retest reliability}

Test-retest reliability was performed to assess Risk-Percept COVID-19's stability by estimating the intraclass correlation coefficient (ICC). Two weeks after the first online compellation of the questionnaire, twenty people were asked to full out and either to send them back. ICC values of .40 and above are considered acceptable [28].

\section{Overall risk perception: linear transition scoring}

The sum of responses across the 29 items was calculated (responses are scored; strongly disagree $=1$; disagree $=2$; neutral 3; agree $=4$; strongly agree $=5$ ). Total scores ranged from 29 to 145 . The sum of scores for 29 answered items were calculated. We used linear transformation to convert to $0-100$ score by subtracting the lowest raw score from the possible raw sum score divided by 116 (the highest score minus the lowest score $(145-29))$ and multiplied by 100 . Lower scores indicating low risk perception, and higher scores indicating a better risk perception.

\section{Results}

Demographic characteristics of the participants for both EFA $(n=225)$ and CFA $(n=195)$ samples are shown in Table 1. 
Table 1

characteristics of participants

EFA sample $\mathrm{n}=\mathbf{2 2 5}$ number

(\%)
CFA sample $n=$ 195

Number (\%)

\section{Age (years)}

\begin{tabular}{lll}
\hline $15-29$ & $48(21.1)$ & $37(18.9)$ \\
\hline $30-44$ & $125(55.1)$ & $118(60.5)$ \\
\hline $45-59$ & $43(18.9)$ & $35(17.9)$ \\
\hline $60+$ & $9(4.0)$ & $5(2.5)$ \\
\hline Mean (SD) & $37.11(11.54)$ & $37.42(10.35)$ \\
\hline Gender & & $70(35.9)$ \\
\hline Male & $77(36.7)$ & $125(64.1)$ \\
\hline Female & $148(63.3)$ & $1(.5)$ \\
\hline Educational status & & $4(2.0)$ \\
\hline Illiterate & $2(.7)$ & $50(25.6)$ \\
\hline Elementary school & $8(2.9)$ & $90(48.7)$ \\
\hline Secondary school & $68(28.1)$ & $1(0.5)$ \\
\hline University & $147(.64 .3)$ & $1(0.5)$ \\
\hline Marital status & & $119(61.1)$ \\
\hline Single & $65(30.2)$ & $15(7.7)$ \\
\hline Married & $142(61.9)$ & $1(0.5)$ \\
\hline Widowed & $18(7.8)$ & \\
\hline Having history of COVID-19 (yes) & $1(0.5)$ & \\
\hline Having story of COVID-19 in family member & $1(0.5)$ & \\
\hline yes) & & \\
\hline
\end{tabular}

\section{Construct validity}

\section{Exploratory factor analysis}

The KMO measure was .819 , and Bartlett's of sphericity was significant $\left(X^{2}=3598.13, p<.0001\right)$, indicating the adequacy of the sample for EFA. For the 29-item scale, eight factors revealed eigenvalues 
greater than 1, describing the $42.97 \%$ variance. Using a varimax rotation of the items, all loaded items 0.4 or above one factor were kept. As shown in Table 2, four factors were found; factor 1 (perceived response efficacy) included seven items (items 5, 7, 3, 6, 4, 2, and 1), factor 2 (defensive responses; reactance 22 and 23 , denial 18, 19, and 25, and avoidance 20 and 21$)$ included eight items $(22,23,21,24,19,20,18$, and 25), factor 3 (perceived self-efficacy) included six items $(13,14,12,9,11$, and 8 ), factor 4 (perceived threats;) included seven items $(16,17,28,27,26,10$, and 29). By looking at the loading items, content of items 1 and 15 were changed and included to the closest factor in content and loading factor value. 


\section{Items}

5. Doing health recommendations is effective in preventing Corona.

7. I think doing necessary health recommendations works in preventing Corona.

3. I believe that by disinfecting the surfaces, I am less likely to get Corona.

6. If everyone in the community follows the principals of home quarantine and stays at home, the Corona cycle will be broken.

4. Drinking and eating fruits and vegetables are effective in maintain the body's immune and ultimately reducing the risk of getting Corona.

2. Regular hand washing prevents Corona.

1. Masks work in preventing Corona.

22. I believe that media have highly exaggerated this disease (reactance).

23. I believe that health staff have highly exaggerated this disease (reactance).

21. I'm not interested in hearing about Corona (avoidance).

24. I believe that this is a government plan, they are trying to amuse people (reactance).

19. God protects me, even if I don't follow the health principles of Corona (denial)

20. When Television or Radio talks about Corona, I flip the channel (avoidance).

18. I think sickness or death are in God's hands, and following the precautionary measures isn't important (denial).

25. I think all people will get Corona willingly or unwillingly (denial).

13. I believe that disinfecting the surfaces and goods are easy for me.

14. It's easy for me to consider health recommendations outside the home.

12. It is easy for me to access masks and disinfectants.

9. It is easy for me to use disinfectants.
$.686 \quad-.131 \quad .210$

.021

$\begin{array}{llll}.623 & -.125 & .384 & -.033\end{array}$

$\begin{array}{llll}.613 & -.016 & .187 & .160\end{array}$

$\begin{array}{llll}.597 \quad-.128 & .176 & .054\end{array}$

$\begin{array}{lll}.588 & -.048 \quad .157\end{array}$

.031

$\begin{array}{llll}587 & -.090 & .275 & .049\end{array}$

$\begin{array}{llll}.218 & -. .177 & -.041 & .387\end{array}$

$\begin{array}{llll}-.119 & .719 & -.005 & -.231\end{array}$

$\begin{array}{llll}-.128 & .711 & -.020 & -.204\end{array}$

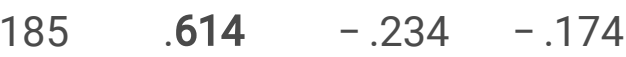

$\begin{array}{llll}-.222 & .604 & .035 & -.015\end{array}$

$\begin{array}{llll}-.057 & .600 & -.002 & .030\end{array}$

$\begin{array}{llll}.085 & .572 & -. .194 & -.074\end{array}$

$\begin{array}{llll}-.193 & .497 & .021 & .047\end{array}$

$\begin{array}{lll}-.303 \quad .399 & .025\end{array}$

.187

$\begin{array}{llll}.218 & -.004 & .749 & .017\end{array}$

$\begin{array}{llll}.100 & -.026 & .704 & -.097\end{array}$

$\begin{array}{llll}.007 & .005 & .670 & -.067\end{array}$

$\begin{array}{llll}.314 & -.011 & .647 & -.024\end{array}$




\begin{tabular}{|c|c|c|c|c|}
\hline Items & & & & \\
\hline 11. I think it's easy for me to wash my hands regularly. & .343 & -.047 & .555 & .026 \\
\hline $\begin{array}{l}\text { 8. I am able to use mask in the closed places with more than } \\
\text { two people. }\end{array}$ & .303 & -.203 & .442 & .123 \\
\hline 16. It is possible that I will contract Corona. & .218 & -.196 & .259 & .168 \\
\hline 17. I am at risk for getting Corona. & -.277 & -.044 & .111 & .620 \\
\hline 28. Corona is a lethal threat. & -.238 & -.132 & -.023 & .580 \\
\hline 27. Possible lung damage from Corona will be serious. & .190 & -.008 & -.107 & .551 \\
\hline $\begin{array}{l}\text { 26. Corona is a serious and dangerous disease due to the high } \\
\text { rate disease transmission. }\end{array}$ & .406 & -.165 & -.136 & .538 \\
\hline 10. Corona is a threat, I think about it. & .081 & .078 & -.034 & .531 \\
\hline $\begin{array}{l}\text { 29. In the current situation, getting many people Corona, } \\
\text { accessing to the treatment is difficult. }\end{array}$ & .328 & -.103 & -.009 & .460 \\
\hline $\begin{array}{l}\text { 15. Fever, cough, and shortness of breath are dangerous } \\
\text { symptoms of Corona. }\end{array}$ & .139 & -.174 & .285 & .387 \\
\hline
\end{tabular}

\section{Confirmatory factor analysis}

A CFA was conducted on the 29-item scale to test the fitness of the model developed through EFA. The results of CFA analysis are shown in Fig. 1. All fit indices were satisfactory. The relative Chi-square was $586.77(\mathrm{P}<.0001)$. The RSMA of the model was $0.056(90 \% \mathrm{Cl}=0.47-0.064)$, and SRMR and CFI were 0.077 and 0.843 , respectively.

\section{Reliability}

In order to measure reliability, Cronbakh's alpha was calculated separately for the Risk-percept COVID-19 as a whole and for each dimension of the Risk-percept COVID-19. Cronbakh's alpha coefficient for the Risk-percept COVID-19 was .741 and ranged from .697 to .793 for the subscale. No items of the questionnaire were deleted in this phases. Furthermore, test- retest analysis was conducted to test the stability of the questionnaire. The results are shown in Table 3. 
Table 3

Measures of internal consistency and stability Risk-percept COVID-19

\begin{tabular}{|lllcc|}
\hline factor & Name of factor & No. items & $\begin{array}{c}\text { Cronbach alpha }(\mathbf{n =} \\
\mathbf{2 1 0})\end{array}$ & $\begin{array}{c}\text { ICC }(n=) \\
\mathbf{2 0})\end{array}$ \\
\hline 1 & $\begin{array}{l}\text { Response } \\
\text { efficacy }\end{array}$ & 7 items $(2-7,15)$ & .793 & .80 \\
\hline 2 & $\begin{array}{l}\text { Defensive } \\
\text { response }\end{array}$ & 8 items $(18-25)$ & .746 & .75 \\
\hline 3 & Self-efficacy & 7 items $(8,9,11,12,13,14)$ & .760 & .72 \\
\hline 4 & Threats & $\begin{array}{l}7 \text { items }(16,17,28,27,26,10, \\
29)\end{array}$ & .697 & .71 \\
\hline
\end{tabular}

\section{Discussion}

In this study, we developed a risk perception scale to measure cognitive appraisal of adults for COVID-19 threat. This study well evaluated the psychometric properties, validity, and reliability of the Rick-percept COVID-19 scale. This EPPM based study provide a measure for evaluating the items with four elements among Iranian adults. Most importantly, we wanted to make a self-report instrument of risk perception available for Iranian research, allowing for future interventional and cross-cultural assessments. A fourdomain was emerged through EFA. Also, a CFA showed acceptable the fit of data. As such, the final Rickpercept COVID-19 contained 29 items, with seven items representing response efficacy, eight items for susceptibility, seven items for self-efficacy, and eight items for severity). Our results indicate that the Rickpercept COVID-19 has sound psychometric properties, good structural validity with acceptable internal consistency across the scale and subscale of the instrument.

During the outbreak of COVID-19, it is important that how people perceive the risk of COVID-19 threat and its effects on their protective behavior. According to EPPM, when people receive a message they initiate two cognitive appraisals; an appraisal of the threat (severity and susceptibility) and an appraisal of the response efficacy. Cognitive appraisal of the threat in our scale was measured with the items such as "Corona is a threat, I think about it" or "I am at risk for getting Corona" (perceived susceptibility) or "Corona is a lethal threat." (perceived severity). Thus, if people have low perceived susceptibility or/and low perceived severity, they won't respond to the COVID-19 threat. In contrast, if people think about the COVID-19 threat and percept that they are vulnerable to the threat, it might lead to serious harm, thus, they scared and motivated to healthy practice against the threat. More the stronger perceived the threat, the greater the fear and the persuasive to have protective behavior $[29,30]$.

When people believe that they are able to perform the recommended response, for example, "It is easy for me to use disinfectants" or "It is easy for me to access masks and disinfectants", they show high perceived self-efficacy, and they believe that doing health recommendations is effective in preventing Coronavirus" or "staying at home" (recommended response) works in averting the coronavirus threat, they have high perceived response efficacy. It's seems that intensive people's perceptions of Coronavirus threat 
and efficacy motivate them to control the danger [31]. In contrast, if people doubt their ability to perform the recommended response for averting Coronavirus threat (low perceived self-efficacy), they doubt whether the recommended response effectively prevent the threat. Therefore, if they have low perceived response efficacy, they believe that there's no use in controlling the danger, thus, rather than controlling the danger, they turn around defensive strategies such as "I believe that health staff have highly exaggerated this disease."

When people block further thoughts about the Coronavirus threat (avoidance response: "when Television or Radio talks about Corona, I flip the channel", or if they refuse that it is possible they can experience the Coronavirus threat (denial response: "God protects me, even if I don't follow the health principles of Corona.", or if they try to pretense that the source of the message deceit people (reactance responses: "I believe that this is a government plan, they are trying to amuse people"), defensive responses occurs [32].

\section{Strengths}

According to EPPM, the key concept of this instrument is to determine people's perception of threat and efficacy toward the Coronavirus pandemic threat and recommended response. Then, the Risk-percept COVID-19 helps researcher to explore the cognitive and emotional mechanisms underlying acceptance or rejection of COVID-19 prevention campaign messages. Interpretation of the instrument's score and the association of it's dimensions indicate that emotion fear is associated with fear control responses (avoidance, denial and reactance) and perceptions or cognitions about recommended response are associated with danger control responses [33]. More specifically, this EPPM based instrument specifies two cognitive process in response to threating COVID-19 information; danger control or fear control responses [34].

\section{Conclusion}

In general, the current findings show that the Risk-percept COVID-19 is a valid and reliable instrument to assess the cognitions and perceptions of adults. Further studies from different cultural and economic backgrounds are suggested to find stronger psychometrics properties.

\section{Abbreviations}

\section{WHO}

World Health Organization; EPPM:extended parallel process model; CFA:Confirmatory factor analysis; CFI:Comparative Fit Index; CVI:Content validity index; CVR:Content validity ratio; EFA:Exploratory factor analysis; GFI:Goodness of Fit Index; ICC:Intraclass correlation coefficient;

\section{Declarations}

Ethics approval and consent to participate 
The study received ethical approval from the Ethics Committee of Tabriz University of Medical

Sciences (NO: IR.TBZMED.REC. 1398.1307). We obtained written informed consent from all participants.

Consent for publication

Not applicable

Availability of data and material

The data collection tools and datasets generated and/or analyzed during the current study are available from the corresponding author on reasonable request.

Competing interests

The authors declare no conflicts of interest.

\section{Funding}

Tabriz University of Medical Sciences provided funding resource.

Authors' contributions

LJ and AM were responsible for the study design. LJ and PS did the analyses. LJ and AM were responsible for data interpretation. PR, SS, and ZS helped in the study design and data gathering, MT and AM helped in the drafting of the manuscript. All authors have read and approved the final manuscript.

\section{Acknowledgments}

We acknowledge the contributions of Tabriz University of Medical Sciences, Tabriz, Iran for providing facilities to the study. Our thanks go to all the respondents of the study for their valuable co-operation.

\section{References}

1. Rothan HA, Byrareddy SN. The epidemiology and pathogenesis of coronavirus disease (COVID-19) outbreak. Journal of Autoimmunity, 2020: p. 102433.

2. https://.

3. https://.

4. McMahan S, Witte K, Meyer Ja. The perception of risk messages regarding electromagnetic fields: extending the extended parallel process model to an unknown risk. Health communication. 1998;10(3):247-59.

5. Witte K, Meyer G, Martell D. Effective health risk messages: A step-by-step guide. 2001.

6. Johnston AC, Warkentin M. Fear appeals and information security behaviors: an empirical study. MIS quarterly, 2010: p. 549-566. 
7. Berger ZD, et al. Covid-19: control measures must be equitable and inclusive. BMJ. 2020;368:m1141.

8. Escher AR Jr. An Ounce of Prevention: Coronavirus (COVID-19) and Mass Gatherings. Cureus. 2020;12(3):e7345.

9. Hu JX, et al. [Risk assessment and early warning of imported COVID-19 in 21 cities, Guangdong province]. Zhonghua Liu Xing Bing Xue Za Zhi. 2020;41(5):658-62.

10. Peto J. Covid-19 mass testing facilities could end the epidemic rapidly. BMJ. 2020;368:m1163.

11. Poole DN, et al. Responding to the COVID-19 pandemic in complex humanitarian crises. Int J Equity Health. 2020;19(1):41.

12. Adhikari SP, et al. Epidemiology, causes, clinical manifestation and diagnosis, prevention and control of coronavirus disease (COVID-19) during the early outbreak period: a scoping review. Infect Dis Poverty. 2020;9(1):29.

13. Contreras GW. Getting ready for the next pandemic COVID-19: Why we need to be more prepared and less scared. J Emerg Manag. 2020;18(2):87-9.

14. Ebrahim SH, et al. Covid-19 and community mitigation strategies in a pandemic. BMJ. 2020;368:m1066.

15. Eurosurveillance Editorial T. Updated rapid risk assessment from ECDC on the novel coronavirus disease 2019 (COVID-19) pandemic: increased transmission in the EU/EEA and the UK. Euro Surveill, 2020. 25(10).

16. Griffith R. Using public health law to contain the spread of COVID-19. Br J Nurs. 2020;29(5):326-7.

17. Agyeman AA, Laar A, Ofori-Asenso R. Will COVID-19 be a litmus test for post-Ebola Sub-Saharan Africa? J Med Virol, 2020.

18. Ali I. The COVID-19 Pandemic: Making Sense of Rumor and Fear. Med Anthropol, 2020: p. 1-4.

19. Liang ZC, Ooi SBS, COVID-19: A Singapore Orthopedic resident's musings in the Emergency Department. Acad Emerg Med, 2020.

20. Manderson L, Levine S. COVID-19, Risk, Fear, and Fall-out. Med Anthropol, 2020: p. 1-4.

21. Shah SGS, Farrow A. A commentary on "World Health Organization declares global emergency: A review of the 2019 novel Coronavirus (COVID-19)". Int J Surg. 2020;76:128-9.

22. Waltz CF, Bausell BR, Nursing research: design statistics and computer analysis. 1981: Davis FA.

23. Lacasse Y, Godbout C, Series F. Health-related quality of life in obstructive sleep apnoea. Eur Respir J. 2002;19(3):499-503.

24. Everitt BS. Multivariate analysis: The need for data, and other problems. The British Journal of Psychiatry. 1975;126(3):237-40.

25. Ferguson E, Cox T. Exploratory factor analysis: A users' guide. International journal of selection assessment. 1993;1(2):84-94.

26. Norris M, Lecavalier L. Evaluating the use of exploratory factor analysis in developmental disability psychological research. J Autism Dev Disord. 2010;40(1):8-20. 
27. Cronbach LJ. Coefficient alpha and the internal structure of tests. psychometrika. 1951;16(3):297334.

28. Munro BH, Statistical methods for health care research. Vol. 1. 2005: lippincott williams \& wilkins.

29. Popova L. The extended parallel process model: Illuminating the gaps in research. Health Education Behavior. 2012;39(4):455-73.

30. Jones JH, Salathe M. Early assessment of anxiety and behavioral response to novel swine-origin influenza A (H1N1). PLoS one, 2009. 4(12).

31. Popova L. The extended parallel process model: illuminating the gaps in research. Health education behavior: the official publication of the Society for Public Health Education. 2012;39(4):455.

32. Tannenbaum MB, et al. Appealing to fear: A meta-analysis of fear appeal effectiveness and theories. Psychological bulletin. 2015;141(6):1178.

33. Witte K. Fear control and danger control: A test of the extended parallel process model (EPPM). Communication Monographs. 1994;61(2):113-34.

34. Witte K, Allen M. A meta-analysis of fear appeals: Implications for effective public health campaigns. Health education behavior. 2000;27(5):591-615.

\section{Figures}

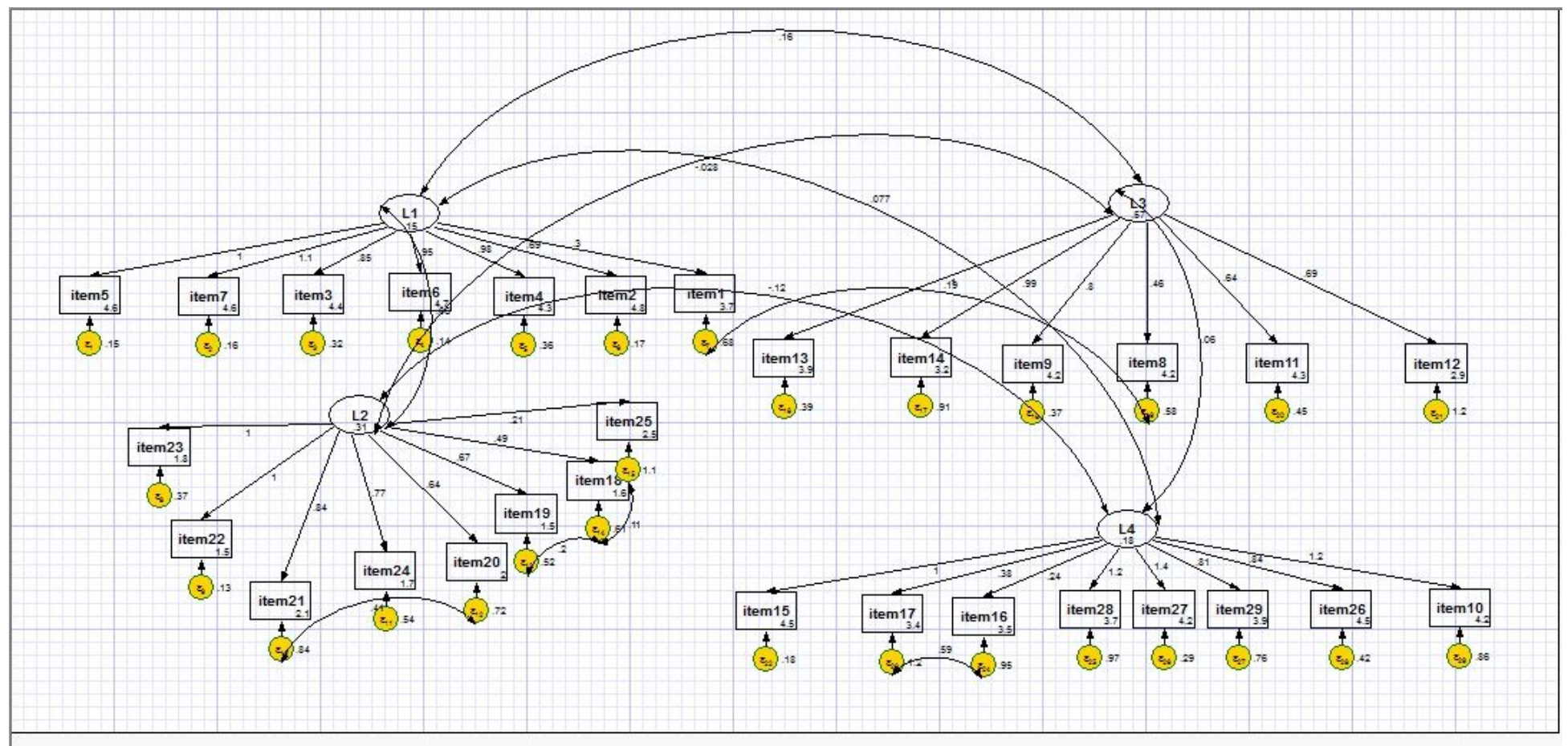

\section{Figure 1}

confirmatory factor analysis 